C 2020 Intellect Ltd Article. English language. https://doi.org/10.1386/jdsp_00027_1 Received 27 September 2019; Accepted 9 October 2020

\title{
Costume as a somatic tool in dance education: A provocation
}

\begin{abstract}
Somatic dance practice is a much needed accompaniment to any dance training, with many benefits to the students. However, breaking through to a sceptical novice student can be a challenge. And for those who fall willingly into the practice, becoming overly internalized and disconnected to the external can be equally problematic. In response to these issues, the author advocates that costume could be the answer. This visual essay will reflect on the absence of costume in dance education and examine its somatic nature through the analysis of relevant performance works. Evidencing costume's haptic nature and impact on the performing body, its comparison with somatic dance practice principles will be discussed. Finally, the author suggests a definition of the somatic nature of costume and its recommendation as a tool to support the teaching of somatic practice in dance education.
\end{abstract}

KEYWORDS: costume, haptic, pedagogy and performance, transformation, agency, empathy

\section{INTRODUCTION}

As a dance student, I had the pleasure of training in a wide variety of somatic dance practices, including the Skinner Releasing Technique, dance movement therapy, authentic movement, improvisation and contact improvisation, yoga and butoh. Engaging with numerous somatic practices helped me... 
to experience my body, implement body-mind integration and internalize my movement.

Whilst studying these practices, I was very much aware that some of my peers were resistant to and/or struggled with the need to be self-aware and internally focused - something I now observe my own performance students grapple with, who are predominantly from formal modern dance and actor training backgrounds. And as much as $\mathrm{I}$, a willing convert to somatics, learnt to be a 'multi-sensorial body' (Dean 2015: 161), my dialogue between the internal and external (self and other) was at times unbalanced, leading to a habit of over-internalization.

As a professional dance artist, I engaged in a five-year relationship with the MA in Costume Design for Performance at London College of Fashion (LCF) as performer and choreographer. This connection allowed me to explore the impact of costume on the performing body, in which I found that costume was an external stimuli that could allow for a re-balancing of my internal and external connections, leading to expressed embodiment.

Through an analysis and comparison of somatic dance practice and my relevant experiences and research, I will identify the somatic nature of costume and argue its introduction as a pedagogical tool to support students in the study of dance somatic practice.

\section{AN ABSENCE OF COSTUME IN DANCE EDUCATION}

We have a vibrant history of costume in dance performance, such as the work of the Ballet Russes, Bauhaus, Alwin Nicholais and Lea Anderson. In fact, when researching her new book Costume in Performance: Materiality, Culture, and the Body (2017), Donatella Barbieri identified several examples throughout history of costume preceding directing the choreography of the performance (Smith 2018). Sadly, the importance of costume as a theatrical element has arguably never fully recovered since the postmodern dance movement stripped away theatricality to reveal the everyday (just picture Yvonne Rainer dancing in t-shirt, chinos and sneakers). Arguably, anything put on the body is a costume, and the choice to wear everyday clothes or none at all is equally valued as a costume choice as more theatrical designs. However, whether due to lack of budget or comprehension, costume has become an under-utilized performative tool in dance. This is particularly reflected in dance education.

In my dance degree and MA we studied the artists and works mentioned above and more, learning to analyse the rich visual aesthetic and meaning costume can bring to performance. However, we never got to see, touch or put on costume designed specifically for performance (Smith 2018), and therefore no opportunity to experience and examine the impact it can have on the body, performance and the devising process. This continued absence of costume on the majority of dance and performance-based UK degree courses echoes Aoife Monk's assertion that costume is an ignored or under-represented element of theatrical performance (2013: 60). As a HE Dance educator, my own surmises on why costume remains absent is likely due to tight department budgets, reduction in module hours and the perpetuation of the lack of costume expertise.

\section{THE SOMATIC NATURE OF COSTUME}

Sondra Fraleigh states that 'when we dance and create we rarely leave our whole self at the door, so external stimuli is used to help the dancer assume a new body' (1987: 30). Costume has the potential to be a highly impactful and... 
somatic external stimuli. In particular, the design elements of a costume can help the wearer re-experience their body and develop in areas such as embodiment and identity transformation.

Examining the main areas in costume design, the use of structure can restrict and/or extend the body in space, developing the wearer's understanding and use of kinaesthetic movement expression and creating a connection

to, and interaction with, the performance environment and the audience. The choice of materials, that is, the texture, weight, colour and so forth, can affect how the wearer feels and moves, with the potential to impact the use of breath and tension in the body. Finally, the use of layers can aide the wearer in the transformation of different emotional and physical states, characters, genders and historical time periods.

An example incorporating all these design choices can be seen in the costume performance piece Ping (2014) by designer Daphne Karstens (Figures 1-3). The costume design included a morph suit, removable mesh and wire tubular structured layer and built-in smoke machine connected to tubes sewn onto the suit. The weighted structured layer greatly restricted my movement and helped me embody a feeling of body paralysis and the image of a cocooned moth. The physicality of removing this layer created an intense sense of muscular and emotional relief, allowing me to embody the transformation into a new entity/astral body. The use of smoke extended my body and movement in space, and created movement traces for the audience to see (Smith 2018: 191).

Through choreographing costume performances and incorporating costume experiences into my own teaching pedagogy: such as 'experiencing costume' workshops, devising student performance work with costume as starting point and facilitating student collaboration projects with the BA Fashion Enterprise course (Figures 4 and 6), I have been able to observe and document (interviews and surveys) the impact of costume on performer development ${ }^{1}$. I have witnessed both untrained performers and degree students at all levels progress their performativity and artistry. Reflecting on their costume experiences students identified significant development in movement vocabulary, creativity, confidence, performance presence and embodiment. They also noted an increased openness to their artistic decisions. But why is costume able to have such a powerful impact on the wearer? And why would it be a useful external stimuli in the support of somatic dance practice?

Costume structure, materials, layers and body fit are all creating a sensorial experience that affects how the wearer feels and moves, including tension in the body and use of breath. Costume is therefore engaging the wearer haptically.

[The] haptic sense [...] is the oldest, most comprehensive and complex of the senses, with receptors embedded throughout the body from the skin down into the joints and muscles [...] a deep well of sensory input.

(Driscoll 2011: 108)

This haptic engagement, along with any material smells, allows for visceral connections and embodied knowledge to be triggered. Machon describes this triggered information as 'the intuitive knowledge that refers human perception back to its primordial impulses, which encompass the emotional and the physiological capabilities of the physical body' (2013: 105). This strong porousness between body and costume can create an internal and external...

\footnotetext{
1 Selection of BA student feedback on working with costume (2016):

'I thought more about what my whole body was conveying to the audience'.

'It has a huge influence on your movement choices'.

'It transforms you into a whole different person'.

'I had the confidence to perform because the costume gave me the power to'.

'The costume allowed me to be present throughout the whole piece and connect with the audience'.

'When you put [the costume] on everything changes, you're whole perception changes'.

'In the beginning my movement was very basic and closed. However, once the costume was added movement became open and risky'.

'The performance for both pieces would have been slightly worthless without the costume to highlight the characters and emotions conveyed'.
} 

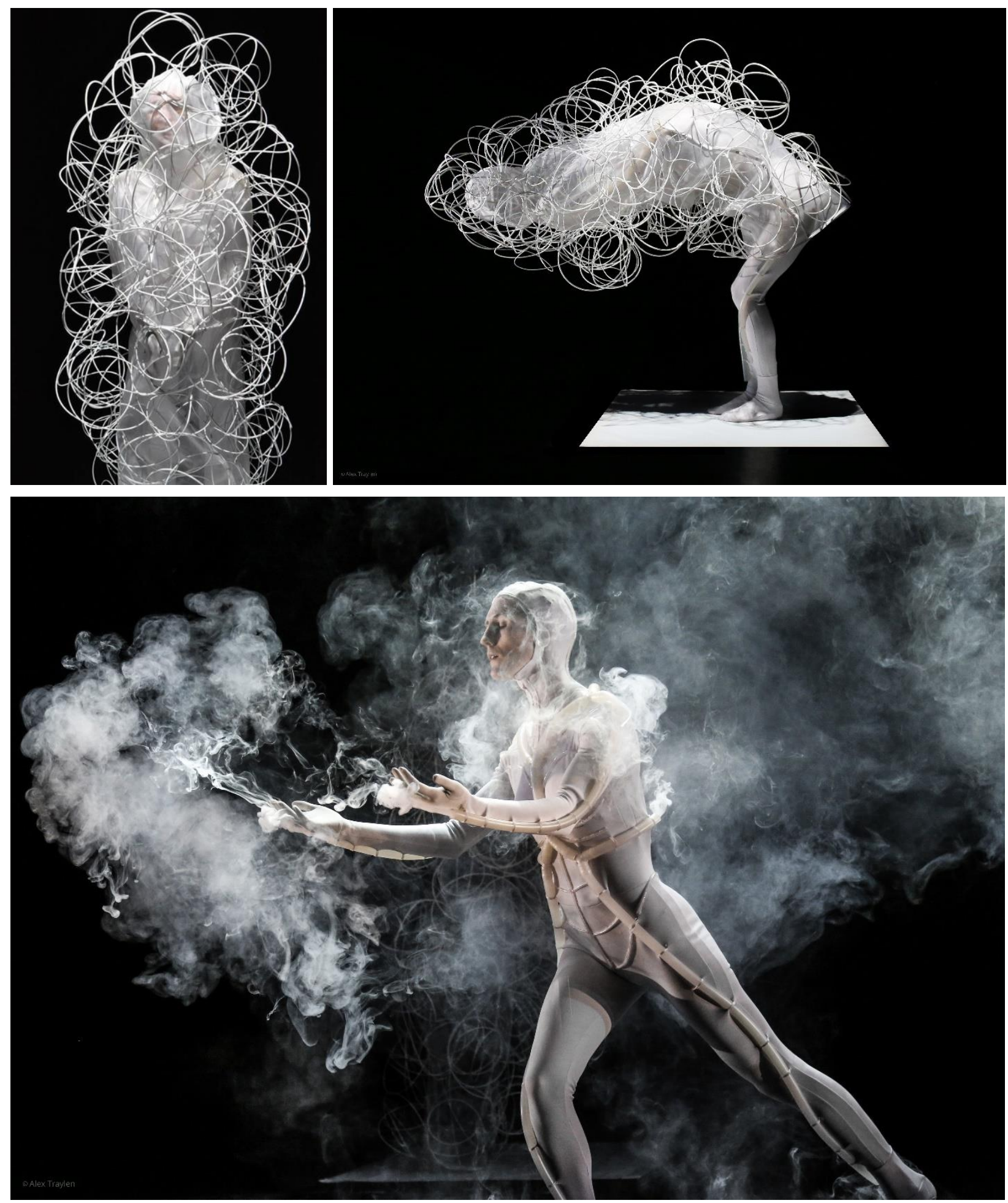

Figures 1-3: Ping (2014). Costume design by Daphne Karstens, choreography by Angela Woodhouse. Photo credit Alex Traylen.

transformation in the wearer that can impact their sense of identity and encourage in Machon's words 'an abandonment of everyday boundaries' (2013: 28). The somatic nature of costume is highlighted further by Dr Rachel Hann in her article 'Costume affects: A theory of hugging' (2012), in which she describes costume as squeezing and gripping the body in what can feel like a nurturing and protective hug, allowing for psychological release.

\section{COSTUME AND SOMATIC DANCE PRACTICE: SHARED PRINCIPLES}

It may seem odd to suggest using an external form, used predominantly in performance, as a tool in practices that emphasize the internal experience. But costume and somatic movement practices share a lot of common principles. Although it must be highlighted that somatic practices are consciously aiming for certain developments in body awareness and functioning, whereas costume is unconsciously achieving very similar outcomes. 
It is clear that both somatics and working with costume develop proprioceptive, kinaesthetic and embodied knowledge via 'improvisational sensory engagement' (Barbour 2016: 193), notably, the use of sensory experience through the skin to awaken awareness. Both may arouse psychological and emotional responses (Cardinal 2014), yet still keep the movers and wearers in relationship with the world.

Looking at Dr Karen Barbour's core somatic dance values: somatic awareness, movement as well-being, agency and freedom and caring and belonging, we can see further connections:

Somatic awareness (paying conscious attention to kinaesthesia and proprioception, emotions and cognitions) Movement as well-being (discovering creativity, experiencing movement diversity, integration and rest through intentional movement alone and with others)

Agency and freedom (identifying habit, options and making choices, expressing autonomy as well as relationship through artistic, intentional and aesthetic movement)

Caring and belonging (practicing self-care and self-healing, demonstrating empathy and compassion, sharing and collaborating with others, leading and teaching to express relationships with others)

(2016: 190-91)

It is clear from the first point, the example of Ping and student reflections ${ }^{1}$, that costume can lead to somatic awareness. Examining the second and third points, I would argue that working from costume can be an extremely enriching and creative experience when the wearer is open to dialogue with the costume, allowing exploration and experimentation of movement and artistic choices beyond the habitual. The final point is a little bit more specific. However, in relation to self-care and understanding, wearing and reacting to costumes that represent or evoke characters and otherness can encourage openness to identity transformation and build empathy towards others. This is re-iterated by Barbieri who affirms that costume, when placed on a moving body, translates 'visually and physically, ideas that can be read by the audience [...] [in which] the audience's own body is reflected in the work presented through identification in a shared humanity' (2012: 148).

This can be seen in the use of costume in the Arts and Humanities Research Council funded project Imagining Autism (University of Kent n.d.). For example, the costume called 'Foxy' was a particular success with the autistic children. The costume design included a mask, fur coat, padding around the hips and a long swinging tail, all which sat heavy on the body (Trimingham and Barbieri 2016). Reflecting on the project Trimingham noted:

When you put that [costume] on instantly you're much taller and it just physically makes you feel different [...] one girl with virtually no speech at all began to start embodying the fox through feeling this costume. She began to develop a kind of empathy with the fox character through moving like Foxy. 

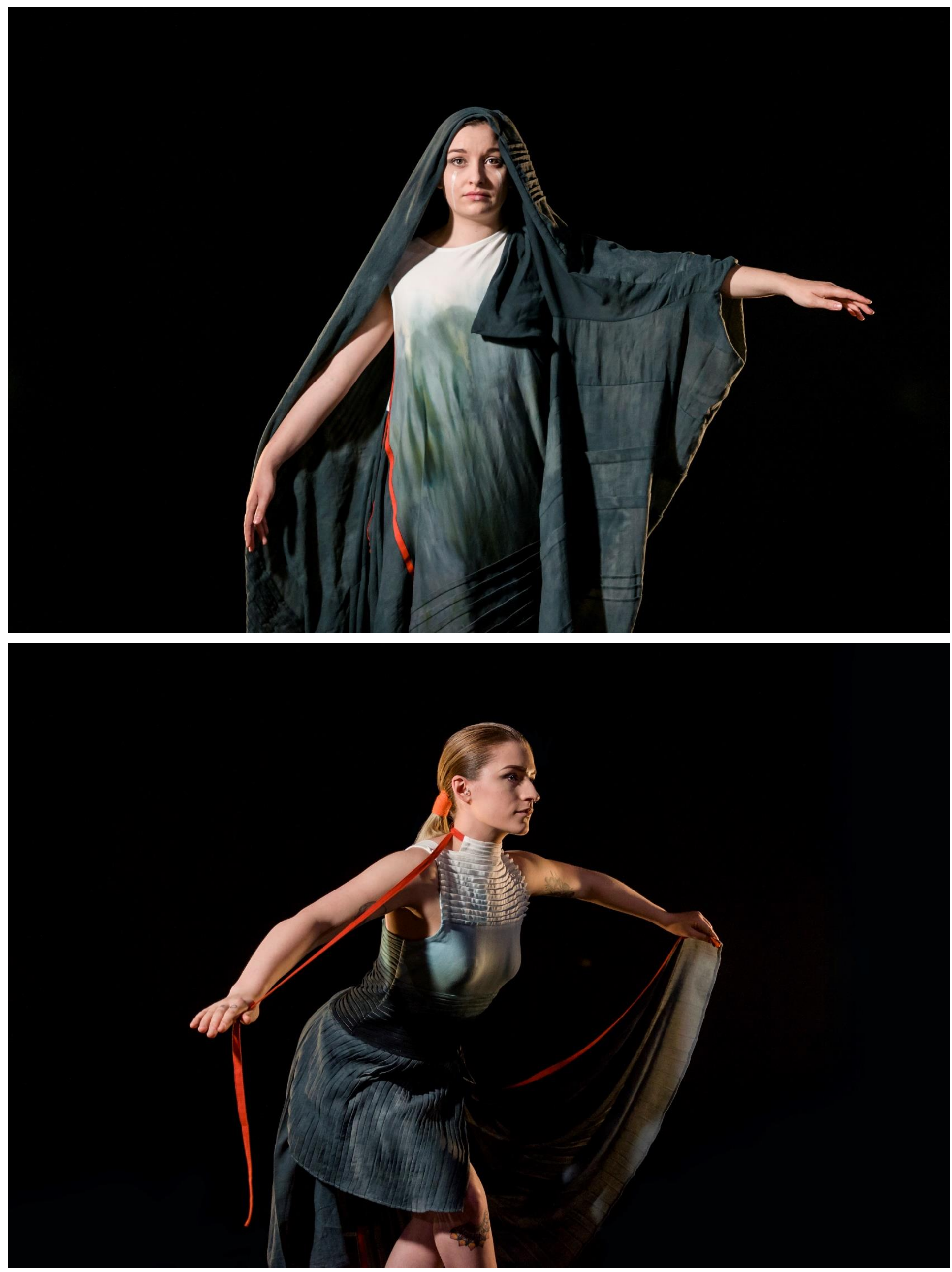

Figures 4 and 5: Abandonment (2016). Costume design by level 4 BA Fashion Enterprise, choreography by Level 6 BA Dance (Teesside University). Photo credit Aaron Blenkin. 


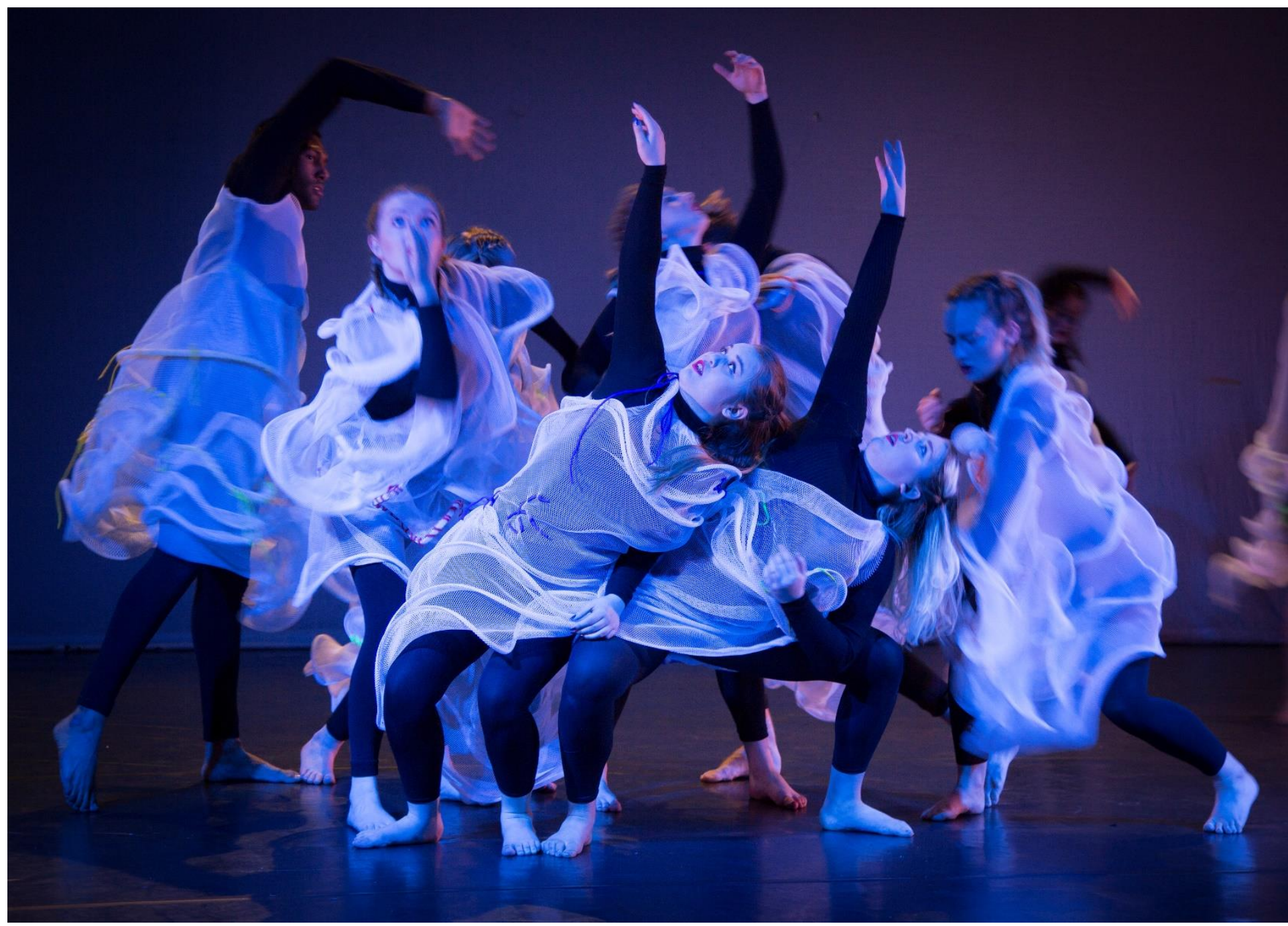

Figure 6: Maritime Futures (2017). Costume design by BA Fashion Enterprise, choreography by Level 4-6 BA Dance (Teesside University). Photo credit David Griffiths.

\section{SUPPORTING SOMATIC TRAINING}

There are several challenges in teaching somatic dance practice where costume could be utilized. Barbour states that 'while the transfer of sensorimotor learning and awareness is a valuable intention, some students may not yet have the capacity to maintain sensory awareness lightly and engage in moving with others' (2016: 194). Costume could therefore be a useful tool to ease students into this type of experiential learning. This is echoed by Martha Eddy, creator of BodyMind Dancing, who discusses how 'A simple tendu sequence can be enhanced by a somatic exercise using real hand brushes to stimulate a sensory experience and wake up the feet' (Eddy cited in Wozny 2010: n.pag.). This use of external tools (in this instance the hands) is akin to Bonnie Bainbridge Cohen' ${ }^{2}$ pioneering somatic work as an occupational therapist in which movement reeducation and hands-on re-patterning is implemented as transformative tools (Bainbridge Cohen 2020: n.pag.).

Barbour (2016) and Masters and Poolton (2012) also question the use of explicit motor learning strategies in somatic education, suggesting that implicit motor learning, where students can acquire movement skills without explicit conscious processes, is more conducive with the technical and performative skills students already have or are engaging in. And that 'analogies that bring attention to an external focus may particularly support implicit motor learning' (Barbour 2016: 200). Again, costume could be a useful implicit external tool in this instance.

\footnotetext{
2 Bonnie Bainbridge Cohen is one of the pioneers of somatics who developed the Body-Mind Centring ${ }^{\circledR}$ approach to movement and consciousness and founded The School for Body-Mind Centring® (Wozny 2010; Bainbridge Cohen 20012020).
} 
Sally Dean, a somatic practitioner, performer, maker and teacher, reinforces the argument for costume as somatic tool, stating:

One way to create awareness and movement re-patterning is through touch and imagery. The costume embodies and integrates both: it touches the body, providing a haptic, kinaesthetic experience while simultaneously instigating a plethora of images, associations and meanings.

Dean has already connected the practices together, creating Somatic Costumes ${ }^{\mathrm{TM}}$ designed in collaboration with costume designers Carolina Rieckhof and Sandra Arroniz Lacunza (Dean 2014: n.pag.). These somatic costume tools, which can be used in educational, artistic and therapeutic contexts, are used to bring awareness to different body areas, generate different movement qualities and experiences in body-mind integration and have the potential to change the wearer's relationship to themselves, others and the environment (Dean 2014, 2016). Part of the process of Dean's somatic costume approach is the eventual removal of the costume, to reveal the 'invisible costume', allowing the mover to awaken the kinaesthetic memory of the discarded costume on the body (Dean 2016). The Somatic Costumes also include 'Companion Costumes', such as a Balloon Hat for two people, which facilitate the wearers in focusing, connecting through and moving from different body parts in space (Dean 2016). Currently only the single wearer Balloon Hat with instructional list of use and exercises can be purchased by educators and artists (Dean 2014: n.pag.).

\section{CONCLUSION}

Hanna wrote somatics recognizes 'that human beings are bodily beings who can become victims of physical and organic forces, but also that they are equally somatic beings who can change themselves' (1988: 21). I agree with Hanna, but also would challenge the notion of becoming a victim to these forces, and that we can choose to engage with external forces to achieve change in ourselves.

During her talk Body-Assemblages at the Innovative Costume of the twenty-first century symposium (2019: n.pag.), scenographer Dr Rachel Hann set out the following provocation:

- that bodies are not fixed,

- that we are always in process and costume can remind us of this,

- that costume can augment an orientation of the self to the environment, others, identity, sexuality, and so on, allowing for play,

- and that costume performances are sustained moments of feelings and emotional states of being, triggering kinaesthetic empathy and embodied memories (for both the performer and viewer).

Therefore, using Hann's statements as a springboard, the International Somatic Movement Education and Therapy Association's definition of somatic movement education (cited in Eddy 2009: 8) can be adapted to explicitly outline the somatic nature of costume, and thus evidence the suitability of costume as a tool in the support of somatic dance practice training: 
Practices of costume play and performance can encompass postural and movement evaluation, communication and guidance through touch and porousness between skin and material, implicit experiential anatomy, identity transformation and the exploration of new movement choices to enhance human processes of psycho-physical awareness and functioning through movement learning.

It is evident that costume is somatic and an impactful tool to help performers, movers and people in general experience their bodies and identities in-flux, connect the internal with the external environment in an embodied and meaningful way and build empathy towards others. Dean stresses that 'costume is an essential somatic resource, and yet it has been largely unnoticed, under-developed and under-researched within its field' (2016: 99). It is therefore critical that the somatic community acknowledges the somatic nature of costume, and more importantly begin to incorporate costume as an impactful tool in the introduction and support of the teaching of somatic practice in dance education, including in the future developments in the field of somatic dance practice research.

\section{REFERENCES}

- Bainbridge Cohen, Bonnie (2001-2020), 'Bonnie Bainbridge Cohen', Body-mind Centering®: An Embodied Approach to Movement, Body and Consciousness, https://www.bodymindcentering.com/about/bonnie-bainbridgecohen/. Accessed 24 May 2020.

- Bainbridge Cohen, Bonnie (2020), 'BODY-MIND CENTERING®', Bonnie Bainbridge Cohen, https://bonniebainbridgecohen.com/pages/body-mindcentering. Accessed 24 May 2020.

- Barbieri, Donatella (2012), 'Costume re-considered', in Endyesthai (To Dress) - Historical, Sociological and Methodological Approaches, Conference Proceedings, Athens, 9-11 April 2010, Endymatologika 4, Athens: Peloponnesian Folklore Foundation, pp. 147-52.

- Barbieri, Donatella (2017), Costume in Performance: Materiality, Culture and the Body, London: Bloomsbury Publishing.

- Barbour, Karen (2016), 'Embodied values and ethical principles in somatic dance classes: Considering implicit motor learning', Journal of Dance \& Somatic Practices, 8:2, pp. 189-204.

- Cardinal, Marita K. (2014), 'SPICE'2S: Wellness dimensions applied to dance with advice for teachers', Journal of Physical Education, Recreation and Dance, 85:3, pp. 3-7.

- Dean, Sally E. (2014), Educational tools: Somatic costumes ${ }^{\mathrm{TM}}$, http://www.sallyedean.com/educational-toolssomatic-costumes/. Accessed 1 July 2019.

- Dean, Sally E. (2015), 'Amerta movement \& somatic costume: Gateways into environment', in S. Whatley, N. Garrett-Brown and K. Alexander (eds), Attending to Movement: Somatic Perspectives on Living in This World, Axminster: Triarchy Press, pp. 155-80.

- Dean, Sally E. (2016), 'Where is the body in the costume design process?', Studies in Costume \& Performance, 1:1, pp. 97-111.

- Driscoll, Rosalyn (2011), 'Aesthetic touch', in F. Bacci and D. Melcher (eds), Art and the Senses, Oxford: Oxford University Press, pp. 107-14. 
- Eddy, Martha (2009), 'A brief history of somatic practices and dance: Historical development of the field of somatic education and its relationship to dance', Journal of Dance \& Somatic Practices, 1:1, pp. 5-27.

- Fraleigh, Sondra H. (1987), Dance and the Lived Body: A Descriptive Aesthetics, Pittsburgh: University of Pittsburgh Press.

- Hann, Rachel (2012), 'Costume affects: A theory of hugging', TaPRA Annual Conference [The Theatre \& Performance Research Association], University of Kent, 5-7 September.

- Hann, Rachel (2019), 'Body-assemblages', conference presentation, Innovative Costume of the 21st Century: The Next Generation, A. A. Bakhrushin State Central Theatre Museum, Moscow, 17-19 June.

- Hanna, Thomas (1988), Somatics: Reawakening the Mind's Control of Movement, Flexibility, and Health, Cambridge: Da Capo Press.

- Karstens, Daphne (2014), Ping, Sadler's Wells Lilian Baylis Studio, London. Choreography by Woodhouse, Angela. Performance by Smith, Lorraine.

- Machon, Josephine (2013), Immersive Theatres: Intimacy and Immediacy in Contemporary Performance, London: Palgrave Macmillan.

- Masters, Richard S. W. and Poolton, Jamie M. (2012), 'Advances in implicit motor learning', in N. J. Hodges and A. M. Williams (eds), Skill Acquisition in Sport, 2nd ed., London and New York: Routledge, pp. 59-75.

- Monks, Aoife (2013), 'Costuming the Shakespearean stage: Visual codes of representation in early modern theatre and culture - review', Theatre Notebook, 67:1, pp. 59-61.

- Smith, Lorraine (2018), 'The costumographer: Revolutions in performance pedagogy', Studies in Costume \& Performance, 3:2, pp. 179-96.

- Trimingham, Melissa and Barbieri, Donatella (2016), 'War, revolution and design: Exploring pedagogy, practicebased research and costume for performance through the Russian avant-garde theatre', Studies in Theatre \& Performance, 36:3, pp. 269-80.

- University of Kent (n.d.), Imagining Autism, https://imaginingautism.org/. Accessed 24 June 2019.

- Wozny, Nancy (2010), 'Taking Somatics off the Mat', Dance Teacher, 8 March https://www.danceteacher.com/taking-somatics-off-the-mat-2392290127.html. Accessed 10 July 2019.

\section{SUGGESTED CITATION}

Smith, Lorraine (2020), 'Costume as a somatic tool in dance education: A provocation', Journal of Dance \& Somatic Practices, 12:2, pp. 255-265, doi: https://doi.org/10.1386/jdsp $00027 \quad 1$

\section{CONTRIBUTOR DETAILS}

Lorraine Smith is a dance artist and senior lecturer at Teesside University. Lorraine was artistic director/choreographer of Silversmith Dance Theatre (2006-2014) and member of UK Arab dance troupe AI Zaytouna (2007-2014), touring contemporary productions in the United Kingdom and internationally. Lorraine graduated from University College Chichester with a first-class degree in dance studies, holds an MA in choreography from Trinity Laban and a PGCHE (HEA Fellowship) from Teesside University. Her passions include devising dance theatre and costume performance, which inform her research into the impact of costume on the performing body, costume as somatic tool, performance pedagogy, identity and 'otherness'. 
Contact: Teesside University, Campus Heart, Southfield Rd, Middlesbrough

TS1 3BX, UK

E-mail: Lorraine.Smith@tees.ac.uk

https://orcid.org/0000-0001-9192-0635

Lorraine Smith has asserted their right under the Copyright, Designs and Patents Act, 1988, to be identified as the author of this work in the format that was submitted to Intellect Ltd. 